\title{
A utilidade eclesial da aprovação das associações
}

The ecclesial usefulness of the approval of associations

Silvana Neckel ${ }^{1}$

\section{Resumo}

O Concílio Vaticano II sinalizou o valor dos leigos na missão da Igreja, na medida em que eles participam do múnus profético, sacerdotal e real de Cristo. Eles exercem sua atividade apostólica e a eles é permitido fundar e administrar associações com o mesmo objetivo da caridade e piedade, para fomentar a vocação cristã no mundo e alcançar finalidades comuns. Contudo para que estas associações possam ser validamente reconhecidas pela Igreja como associações de fiéis e participar ativamente de sua missão, devem cumprir requisitos determinados pela legislação canônica, dentre estes submeter seu estatuto a análise e aprovação da autoridade eclesiástica. A associação de fiéis é uma forma associativa de apostolado, pois os cristãos que dela participam se comprometem com a sociedade cristã de forma permanente, estas associações tem grande capacidade de evangelização e dialogo com o mundo, pois estão presentes em vários segmentos e setores da sociedade.

\section{Palavras-chave}

Associações. Fiéis. Igreja. Estatuto. Direito Canônico.

Silvana Neckel é advogada atuante no escritório Almeida \& Neckel Advocacia e Consultoria Jurídica nas áreas de Direito Canônico, Direito Civil e Direito Penal. Especialista em Direito Penal, Processo Penal e Direito Processual Civil. Mestranda em Direito Canônico no Instituto Superior de Direito Canônico Santa Catarina - ISDC/SC. 


\section{Introdução}

As associações de fiéis sempre existiram na Igreja, contudo nos últimos anos esse modo de associação tem sido mais frequente. O presente artigo tem o objetivo, num primeiro momento, trazer uma breve contextualização histórica do fenômeno associativo dos cristãos, sua finalidade e valor para a Igreja, para em seguida apresentar o conceito, utilidade e organização das associações de fiéis, e por fim verificar os elementos essenciais que devem conter os estatutos, no intuito de esclarecer qual a utilidade para a Igreja ao aprovar o estatuto de uma associação de fiéis.

\section{As associações de fiéis}

Desde os primeiros séculos do cristianismo, os cristãos se associavam de acordo com as leis do Império Romano, inicialmente constituíam grupos com finalidades caritativas e funerárias. A partir da declaração de Constantino que tornou o cristianismo uma religião lícita, foram criadas inúmeras formas associativas de todos os gêneros, entre leigos, religiosos e sacerdotes seculares ${ }^{2}$.

Ao tratar do apostolado dos leigos, o Concílio Vaticano II, especificamente no Decreto Apostolicam Actuositatem, sinalizou o valor da participação dos leigos na missão da Igreja, pois na Igreja há diversidade de ministérios, mas unidade de missão. Lembra o decreto que no mesmo sentido que Cristo conferiu aos apóstolos e aos seus sucessores, o múnus de ensinar, santificar e de governar em seu nome, os leigos como participantes desse múnus, exercem sua atividade apostólica para a evangelização e santificação dos homens e, para animarem e aperfeiçoarem com o espirito evangélico a ordem das coisas temporais, de tal forma que sua ação seja testemunho de Cristo e colabore para a salvação dos homens ${ }^{3}$.

SISTACH Lluís Martínez, As associações de fiéis. 1. ed., Edições Fons Sapientiae, São Paulo, 2018, p. 21.

3 CONCÍlIO VATICANO II. Decreto Apostolicam Actuositatem. $1^{\mathrm{a}}$ ed., Editora Paulus, São Paulo, 1997, n. 1, 2. 
No mesmo sentido a Exortação Apostólica Christifideles Laici destaca a necessidade de cada fiel leigo ter sempre viva em sua consciência de que é um membro da Igreja, a quem é confiado um encargo original insubstituível e indelegável, e que deverá desempenhar para o bem de todos ${ }^{4}$.

Seguindo esta linha do Concílio o Código Canônico afirma o direito de associação do fiel no cânon 215 , destacando que os fiéis podem livremente fundar e dirigir associações, com a finalidade de caridade ou piedade, sendo útil para fomentar a vocação cristã no mundo, e em conjunto com demais fiéis prosseguir em comum com os mesmos fins ${ }^{5}$.

O fundamento do direito de associação dos fiéis é destacado no Decreto Apostolicam Actuositatem, que expõe: “o homem é, por sua natureza, social e de que aprouve a Deus reunir todos os que creem em Cristo para fazer deles o povo de Deus (cf. 1Pd 2,5-10) e um só corpo (cf.1Cor 12,12)". Nesse sentido o apostolado organizado em associações corresponde às exigências humanas e cristãs dos fiéis, apresentando-se ainda como sinal da comunhão e unidade da Igreja em Cristo, que disse: "Onde estão dois ou três reunidos em meu nome, aí estou no meio deles" (Mt 18,20) ${ }^{6}$.

Os diversos modelos de associações de fiéis são formados somente por leigos, ou por leigos e clérigos, os quais se empenham para fomentar uma vida mais perfeita, por promover o culto público ou a doutrina cristã, ou outras obras de apostolado, como a evangelização, as obras de piedade ou de caridade, e por informar a ordem temporal com espírito cristão, de acordo com o cânon 298 do Código de Direito Canônico, ${ }^{7}$.

Francisco aponta para a importância e riqueza que representam para a Igreja as diferentes formas de associação de fiéis, como as insti-

4 JOÃO PAULO II, Exortação apostólica Christifideles Laici (30 de dezembro de 1988). $1^{a}$ ed., Edições Loyola, São Paulo, 1989, n. 29.

5 IOANNES PAULUS PP.II, Codex Iuris Canonici, Constitutuione Apostolica: Sacrae disciplinae leges, (25 ianuarii 1983), c. 215, Edições Loyola, São Paulo, 2017.

6 CONCÍliO VATICANO II. Decreto Apostolicam Actuositatem. $1^{\mathrm{a}}$ ed., Editora Paulus, São Paulo, 1997, n. 18.

7 CIC-1983, c. 298. 
tuições eclesiais, comunidades, movimentos, pois elas evangelizam todos os ambientes e setores, e sua capacidade de diálogo com o mundo renova a Igreja ${ }^{8}$.

Nesse sentido a finalidade das associações de fiéis é levar a todo o povo a mensagem divina, e participar ativamente da missão da Igreja. O Catecismo da Igreja Católica afirma que os leigos, em virtude do Batismo e da Confirmação, tem a obrigação e gozam do direito, seja individualmente ou organizados em associações, de trabalhar para que a mensagem divina da salvação seja conhecida e recebida por todos os homens e por toda a terra? .

A nova visão a partir do Concilio Vaticano II acerca do direito de associação dos fiéis e o âmbito das associações de fiéis provocou na Igreja, o crescimento de associações laicais tanto em número como na diversidade de dimensões e objetivos, mas com a normal exigência de uma dimensão apostólica ${ }^{10}$.

\section{Conceito e utilidade das associações}

Associação no sentido genérico é um grupo de pessoas com objetivos em comum, que se unem com intuito de alcançar suas finalidades, mediante uma organização reconhecida pelo direito. A associação de fiéis tem elementos constitutivos próprios, sem os quais ela não pode existir, como: seus membros; a finalidade comum; o suporte estrutural; a intervenção da autoridade eclesiástica e a estabilidade. Nas associações de fiéis seus membros são pessoas físicas, ou seja, os fiéis cristãos batizados em Cristo ${ }^{11}$. São considerados fiéis os ministros ordenados, os leigos e os religiosos.

8 JOÃO PAULO II, Exortação apostólica Evangelii Gaudium (24 de novembro de 2013). Edições Loyola, São Paulo, 2013, n. 29.

9 JOÃO PAULO II, Catecismo da Igreja Católica, promulgado pela Constituição Apostólica Fidei deppositum: (11 de outubro de 1992). Edições Loyola, São Paulo, 1999, n. 900.

10 MARCELINO, D. Antônio, As associações na igreja: actas/xii Jornada de direito canônico, 1. ed. Universidade católica editora, Lisboa, 2005, p. 308.

11 SISTACH, Lluís Martínez, As associações de fiéis. 1. ed., Edições Fons Sapientiae, São Paulo, 2018, p. 52. 
Esta maneira de evangelizar, a partir das associações de fiéis, é extremamente útil à nova dimensão pastoral da Igreja, pois traz um verdadeiro estímulo à espiritualidade e ao compromisso apostólico dos leigos. Nesse sentido João Paulo II recorda a expressão elucidativa de S. Gregório Magno quando diz: "Na santa Igreja cada um é apoio dos outros e os outros são seu apoio"12. O apostolado das associações se torna mais capilar na medida em que o evangelho é levado pelos membros das associações a todos que participam de sua vida cotidiana, além de ser constante e incisiva, pois na partilha das condições de vida, no trabalho, nas dificuldades e esperanças dos irmãos, os fiéis atingem o coração de seus vizinhos, amigos e colegas, abrindo seus horizontes para a comunhão com Deus e entre os homens ${ }^{13}$.

Daniel Cenalmor ressalta que associação é uma união estável de pessoas, na Igreja, pelo menos três, as quais perseguem a certos fins para o bem comum dos associados ou de outras pessoas. Lembra que o direito de associação é um direito humano fundamental, o qual é reconhecido em muitos Estados, porém não deriva de uma concessão da autoridade civil, por ser um direito natural. Esse direito é defendido constantemente pelo magistério da Igreja e pela doutrina canônica ${ }^{14}$.

Nesse sentido o código de direito canônico garante a liberdade de associação dos leigos, os quais podem fundar, de acordo com a classificação do código, associações de fiéis privadas ou públicas. As privadas são constituídas pelos fiéis que comungam do mesmo objetivo e finalidade de fomentar uma vida mais perfeita, promover o culto público ou a doutrina cristã, ou a promoção de outras obras do apostolado como a evangelização, obras de caridade e piedade, e animação da ordem temporal com espírito cristão ${ }^{15}$, servindo à missão da Igreja no mundo.

Estas associações privadas para que possam existir juridicamente devem ter seus estatutos revisados e devidamente aprovados pela

12 JOÃO PAULO II, Exortação apostólica Christifideles Laici (30 de dezembro de 1988). $1^{\text {a }}$ ed., Edições Loyola, São Paulo, 1989, n. 28.

13 MARCELINO, D. Antônio, As associações na igreja: actas/xii Jornada de direito canônico, 1. ed. Universidade católica editora, Lisboa, 2005, p. 310.

14 CENALMOR, Daniel, Comentario exegético al código de derecho canónico, 3. ed. EUNSA, 2002, p. 109-110.

15 CIC-1983, c. $298,299 \S 1$. 
autoridade eclesiástica, que após aprovação a constituirá por decreto ${ }^{16}$. A administração caberá aos fiéis, segundo prescrição do estatuto, no entanto estas associações estarão sujeitas a vigilância da autoridade eclesiástica competente, a qual cabe cuidar que nelas se conserve a integridade da fé e dos costumes e não se pratique abusos na disciplina eclesiástica. Assim a autoridade eclesiástica tem o dever e o direito de visitar essas associações e vigiar sua atuação ${ }^{17}$, contudo a aprovação dos estatutos e a vigilância pela autoridade eclesiástica competente não altera a natureza privada da associação.

Luis Navarro ressalta a utilidade da revisão e aprovação dos estatutos e da vigilância da associação pela autoridade eclesiástica, na medida em que o direito canônico dá proteção legal a associação e seus membros, pois a configuração da associação não mudará facilmente e os membros saberão através do disposto no estatuto, as regras associativas, sua posição na associação, bem como seus direitos e deveres $^{18}$.

A administração dos bens da associação é realizada pelos fiéis de acordo com o estatuto, mas a autoridade eclesiástica deverá cuidar para que estes bens sejam utilizados para os fins da associação, devendo intervir no caso de desvio de sua finalidade ${ }^{19}$. A extinção da associação privada de fiéis se dará conforme disposto no seu estatuto, podendo ser supressa pela autoridade eclesiástica competente, verificado que sua atividade resulta grave dano para a doutrina, para a disciplina eclesiástica, ou escandalize os fiéis ${ }^{20}$.

Destaca José Fuentes que o código canônico no cânon 323 não trata somente de autonomia, de regime ou somente de vigilância, mas mostra como se complementam estes aspectos, pois a autonomia que caracteriza a direção e governo da associação privada deve se harmonizar com a vigilância e regime da autoridade eclesiástica ${ }^{21}$.

\footnotetext{
CIC-1983, c. $322 \S 1, \S 2$.

CIC-1983, c. $305 \S 2$, c. $323, \S 1$.

8 NAVARRO, Luis, Le associazioni nella chiesa, 1. ed. Lebreria editrice vaticana, 1999, p. 41.

CIC-1983, c. $325 \S 1$.

20 CIC-1983, c. 326.

21 FUENTES, José A., Comentario exegético al código de derecho canónico. 3. ed. EUNSA, 2002, p. 524.
} 
A pessoa jurídica pública ou privada tem por natureza uma existência perpétua, mas devem prever em seus estatutos sua forma de extinção. No caso das associações privadas a sua extinção e o destino de seus bens se dará conforme prescrição estatutária. Contudo seus bens poderão ter destino diverso, salvo os direitos adquiridos e a vontade dos doadores.

Do mesmo modo que as associações privadas de fiéis, as associações públicas têm como objetivo auxiliar a Igreja a cumprir sua missão no mundo, mas esta forma de associação difere das demais, pois são erigidas unicamente pela autoridade eclesiástica, e se propõe a ensinar a doutrina cristã e promover o culto público em nome da Igreja, ou ainda a outros fins, cuja obtenção está reservada, por sua natureza, a mesma autoridade eclesiástica ${ }^{22}$. Estas finalidades das associações públicas estão explícitas no cânon 301, as quais são exclusivas destas associações e, as que perseguem este fim devem necessariamente ser constituídas como públicas, ficando excluídos estes fins das associações privadas ${ }^{23}$.

$\mathrm{O}$ direito canônico determina quais as autoridades eclesiásticas competentes para a ereção das diversas formas de associações públicas de fiéis, cabendo a Santa Sé a ereção das associações universais e internacionais; a Conferência dos Bispos a ereção das associações nacionais e, ao Bispo Diocesano as associações diocesanas ${ }^{24}$. A autoridade competente para erigir a associação deverá aprovar seu estatuto, bem como sua revisão e modificação. Também caberá a autoridade eclesiástica competente a vigilância da associação pública.

Navarro orienta para que as necessárias reformas dos estatutos ocorram num clima de diálogo, evitando a interrupção dos planos da associação, mantendo sua natureza e respeitando as competências próprias da autoridade que a tenha erigido. Para a aprovação das sucessivas mudanças no estatuto requer um novo decreto da autoridade eclesiástica ao qual será anexado o estatuto alterado ${ }^{25}$.

22 CIC-1983, c. $301 \S 1, \S 2, \S 3$.

23 SISTACH, Lluís Martínez, As associações de fiéis. 1. ed., Edições Fons Sapientiae, São Paulo, 2018, p. 77.

24 CIC-1983, c. $312 \S 1, \S 2$, c. 314.

25 NAVARRO, Luis Felipe, Comentario exegético al código de derecho canónico. 3. ed. EUNSA, 2002, p. 485. 
No que concerne aos bens temporais pertencentes às associações públicas, estes são considerados bens eclesiásticos e neste sentido cabe a autoridade eclesiástica, segundo sua competência, a vigilância sobre a administração destes bens ${ }^{26}$.

A extinção das associações públicas se dará pelo decreto emitido pela autoridade eclesiástica competente, nesse sentido as associações erigidas pela Santa Sé serão suprimidas somente por esta; as Conferências Episcopais podem suprimir associações erigidas por elas em casos graves; o Bispo Diocesano poderá suprimir as que foram erigidas por ele, contudo a autoridade não suprimirá uma associação pública sem antes ouvir seu presidente e os demais oficiais maiores ${ }^{27}$. Poderão ser suprimidas pela regra do direito canônico, o qual estabelece que a pessoa jurídica se extinga, caso suas atividades cessem pelo prazo de cem anos ${ }^{28}$.

Quanto ao destino dos bens da pessoa jurídica de direito público, ou seja, da associação pública de fiéis extinta, dispõe o código canônico que tanto seus bens, quanto os direitos patrimoniais e ônus, devem reger-se pelo seu estatuto e pelo direito, e no caso de omissão, serão adjudicados à pessoa jurídica imediatamente superior ${ }^{29}$. Nesse sentido no caso de supressão de uma associação pública de fiéis de uma diocese, sendo omisso seu estatuto quanto ao destino dos bens, estes passarão a pertencer à diocese.

\section{O estatuto das associações}

Os estatutos são fundamentais para a existência das associações, eles dispõem sobre suas normas regimentais, que não podem ser contrárias ao direito comum e ao direito da Igreja. O estatuto deverá ser elaborado pelos fundadores da associação. $O$ código canônico conceitua estatuto como sendo as determinações estabelecidas de acordo com o direito nas universalidades de pessoas ou de coisas, por meio

\footnotetext{
CIC-1983, c. 1257.

CIC-1983, c. $320 \S 1, \S 2, \S 3$.

CIC-1983, c. $120 \S 1$.

CIC-1983, c. 123.
} 
das quais são definidos sua finalidade, constituição, regime e modo de $\operatorname{agir}^{30}$.

Todas as associações de fiéis sejam elas públicas ou privadas, independente de seu nome ou título, devem ter seus estatutos, e neles conter sua finalidade ou objeto social; endereço de sua sede; descrição de seu regime; condições para ser membro; e os planos de ação conforme o tempo e lugar estabelecido ${ }^{31}$.

Lembra Navarro que o estatuto é um instrumento útil que se adapta as necessidades e finalidades específicas das diversas formas de associações, estas normas de acordo com as demais, regulam e organizam a vida de uma associação, permitindo que ela caminhe de acordo com sua finalidade e o direito da Igreja ${ }^{32}$.

Os estatutos devem contemplar as diversas situações evitando conflitos e problemas insanáveis. Uma das exigências da legislação canônica é a descrição da natureza canônica da associação que se pretende constituir, informando se tratar de uma associação privada ou pública, destacando que é reconhecida, ou aprovada, ou erigida, pela autoridade competente, o Bispo Diocesano, a Conferência Episcopal ou a Santa Sé, conforme o âmbito territorial da associação. Necessário acrescentar que a associação se rege por seu estatuto, pelas normas canônicas, pelo direito comum e o direito particular vigente ${ }^{33}$.

Os estatutos de uma associação obrigam diretamente seus membros, e após a revisão e aprovação obriga de modo indireto a autoridade, pois muitas de suas funções estarão estabelecidas no estatuto. Da mesma forma obrigam de modo indireto as restantes associações, e os demais fiéis, vez que todos devem respeitar a atuação da associação conforme seu estatuto ${ }^{34}$.

Com relação ao nome ou título da associação, deve ser escolhido um que a identifique e distinga das demais, contudo o código indica

30 CIC-1983, c. $94 \S 1$.

31 CIC-1983, c. $304 \S 1$.

32 NAVARRO, L. Felipe, Comentario exegético al código de derecho canónico. 3. ed. EUNSA, 2002, p. 449.

33 SISTACH, Lluís Martínez, As associações de fiéis. 1. ed., Edições Fons Sapientiae, São Paulo, 2018, p. 61-62.

34 NAVARRO, L. Felipe, Comentario exegético al código de derecho canónico. 3. ed. EUNSA, 2002, p. 450. 
que seja adequado aos usos do tempo e lugar, e ressalta a finalidade a que ela se destina. A definição "católica", no entanto, somente pode ser utilizada com o consentimento da autoridade eclesiástica competente ${ }^{35}$.

O domicílio ou a sede da associação deve ser descrito no inicio do estatuto, pois este é o local em que realizará parte de suas atividades, receberá correspondências e determinará a sede jurídica que obrigará a associação no direito particular e o ordinário a qual se reportará. $\mathrm{O}$ estatuto indicará se a sede é propriedade da associação e a competência do órgão supremo da associação em alterar a mudança do domicilio, a qual deverá uma vez alterada ser comunicada a autoridade competente ${ }^{36}$.

Os fins ou objetivos sociais da associação deverão ser determinados logo em seguida, a partir desta descrição é possível saber quais as atividades que a associação realizará para alcançar suas finalidades e a partir destas configurar como associação privada ou pública. Estas finalidades serão objeto de vigilância da autoridade eclesiástica, por isso a importância de que sejam utilizadas expressões concretas, ressaltando que para a associação constituir-se como canônica, é preciso que suas finalidades se enquadrem no cân. 298 , § 1, e que sejam coerentes com a missão da Igreja ${ }^{37}$.

Quanto aos membros que fazem parte ou farão parte da associação cabe salientar a importância deste item no estatuto, face seu caráter perpétuo e democrático participativo. Os estatutos devem estabelecer a natureza e condição dos membros, os requisitos exigidos para se tornar membro, o procedimento para admissão de novos membros, o procedimento para a saída dos membros, e os direitos e obrigações dos membros da associação ${ }^{38}$.

É necessário regular as formas de governo da associação, os órgãos e cargos que serão criados e ocupados, pois o direito particular

35 CIC-1983, c. $300,304, \S 2$.

36 SISTACH, Lluís Martínez, As associações de fiéis. 1. ed., Edições Fons Sapientiae, São Paulo, 2018, p. 62-63.

37 SISTACH, Lluís Martínez, As associações de fiéis. 1. ed., Edições Fons Sapientiae, São Paulo, 2018, p. 64.

38 SISTACH, Lluís Martínez, As associações de fiéis. 1. ed., Edições Fons Sapientiae, São Paulo, 2018, p. 65 
regula somente as funções do presidente e do capelão ou assistente eclesiástico. A assembleia geral e a junta diretiva são órgãos de governo na associação, a assembleia geral é o órgão supremo da associação e participam dela todos os membros com voz e voto, pelo menos os ordinários. Nesse sentido é necessário que o estatuto defina as funções próprias das assembleias gerais ordinárias e extraordinárias.

A junta diretiva é um órgão executivo que cumpre as decisões tomadas nas assembleias, geralmente quem a integra são o presidente, o vice-presidente, o secretario, o tesoureiro, os vogais e o capelão ou conselheiro. Deve ser fixada no estatuto a função e competência do órgão executivo e o numero mínimo de reuniões anuais. Deverá trazer neste item do estatuto os cargos diretivos da associação, o procedimento para designá-los, sua duração e forma de eleição.

$\mathrm{O}$ estatuto deve regular o quórum das reuniões, pois as decisões são tomadas em reuniões dos órgãos de governo. No caso de atos colegiais de associações com personalidade jurídica pública ou privada, o código determina que para a tomada de decisões seja necessária a presença da maioria dos que devem ser convocados, tratando-se de maioria absoluta. A esse respeito é interessante que se repita no estatuto o disposto na legislação canônica ${ }^{39}$.

As associações devem dispor em seus estatutos sobre a forma de administração de seus bens, sendo necessário figurar as formas de aquisição, administração e alienação destes bens, deixando claro que ela poderá administrar estes bens segundo as normas de seu estatuto e do direito. Deve ser determinado o órgão competente para aprovar a formalização dos contratos, a necessidade de financiamento, e os requisitos a serem verificados no caso de alienação de bens ${ }^{40}$.

As faculdades das autoridades eclesiásticas devem fazer parte dos estatutos das associações de fiéis bem como, o direito de visita e inspeção de todas as atividades da associação; a aprovação das contas anuais; a exigência a qualquer tempo da prestação detalhada das contas; o reconhecimento, as modificações nos estatutos; a dissolução da

39 CIC-1983, c. $119, \S 1, \S 2, \S 3$.

40 SISTACH, Lluís Martínez, As associações de fiéis. 1. ed., Edições Fons Sapientiae, São Paulo, 2018, p. 72. 
associação em alguns casos; e as demais competências que o direito canônico e particular concede a autoridade eclesiástica nesse âmbito ${ }^{41}$.

\section{Conclusão}

As associações de fiéis é uma forma de apostolado em que os cristãos batizados exercem sua missão juntamente com a Igreja, participando do múnus de ensinar, santificar e governar em nome de Cristo. $\mathrm{O}$ seu reconhecimento enquanto pessoa jurídica canônica é de suma importância para a Igreja, vez que a partir de sua ereção pela autoridade eclesiástica, ela passa a fazer parte das pessoas jurídicas eclesiásticas e ser sujeito de direitos e deveres.

Criada a associação, esta deverá cumprir o disposto em seus estatutos, na legislação canônica, no direito comum, comunicando-se também com o direito civil do país em que estabelecer sua sede e obter seu registro. $\mathrm{O}$ direito canônico garante a autoridade eclesiástica $\mathrm{o}$ direito de aprovar, revisar e modificar os estatutos e vigiar as atividades das associações, podendo em caso de desvio de finalidades promover sua dissolução.

Nesse sentido verifica-se que para a Igreja é extremamente útil que os estatutos destas associações de fiéis sejam avaliados e aprovados pelas autoridades eclesiásticas, pois a finalidade destas associações está diretamente ligada à missão da Igreja e ao apostolado de Cristo. Esta aprovação traz segurança a Igreja de que as associações cumprirão seu apostolado atendendo às regras do direito canônico, e as necessidades da comunidade cristã, primando pelo bem de todos e pelas obras de caridade e piedade.

\section{Bibliografia}

CESAR DE LIMA, MURILO, Introdução à historia do direito Canônico. $2^{\mathrm{a}}$ ed., Edições Loyola, São Paulo, 2004, p. 31,32.

41 SISTACH, Lluís Martínez, As associações de fiéis. 1. ed., Edições Fons Sapientiae, São Paulo, 2018, p. 72-73. 
CENALMOR, Daniel, Comentario exegético al código de derecho canónico. 3. ed. EUNSA, 2002.

CONCÍlIO VATICANO II. Decreto Apostolicam Actuositatem. $1^{\mathrm{a}}$ ed., Editora Paulus, São Paulo, 1997.

FUENTES, José A., Comentario exegético al código de derecho canónico. 3. ed. EUNSA, 2002.

GERALDO, Denilson, Metodologia jurídica canônica. 1. ed., Editora Santuário, São Paulo, 2010.

JOÃO PAULO II, Codex Iuris Canonici, Constitutuione Apostolica: Sacrae disciplinae leges,(25 ianuarii 1983), Edições Loyola, São Paulo, 2017.

JOÃO PAULO II, Catecismo da Igreja Católica, promulgado pela Constituição Apostólica Fidei deppositum: (11 de outubro de 1992). Edições Loyola, São Paulo, 1999.

JOÃO PAULO II, Exortação apostólica Christifideles Laici (30 de dezembro de 1988). $1^{\text {a }}$ ed., Edições Loyola, São Paulo, 1989.

JOÃO PAULO II, II, Exortação apostólica Evangelii Gaudium (24 de novembro de 2013). Edições Loyola, São Paulo, 2013.

MARCELINO, D. Antônio, As associações na igreja: actas/XII Jornada de direito canônico, 1. ed. Universidade católica editora, Lisboa, 2005.

NAVARRO, Luis Felipe, Comentario exegético al código de derecho canónico. 3. ed. EUNSA, 2002.

NAVARRO, Luis, Le associazioni nella chiesa, 1. ed. Lebreria editrice vaticana, 1999.

SISTACH, Lluís Martínez, As associações de fiéis. 1. ed., Edições Fons Sapientiae, São Paulo, 2018. 